Article

\title{
Entropy Measures of Street-Network Dispersion: Analysis of Coastal Cities in Brazil and Britain
}

\author{
Nahid Mohajeri $^{1, *}$, Jon R. French ${ }^{2}$ and Agust Gudmundsson ${ }^{3}$ \\ 1 Department of Geography, University College London, Gower Street, London WC1E 6BT, UK \\ 2 Environmental Modelling and Earth Observation Group, UCL Department of Geography, \\ University College London, Gower Street, London WC1E 6BT, UK; E-Mail: j.french@ucl.ac.uk \\ 3 Department of Earth Sciences, Queen's Building, Royal Holloway University of London, \\ Egham TW20 0EX, UK; E-Mail: a.gudmundsson@es.rhul.ac.uk \\ * Author to whom correspondence should be addressed; E-Mail: nahid.mohajeri.09@ucl.ac.uk; \\ Tel.: +44-778-877-5101.
}

Received: 4 July 2013; in revised form: 3 August 2013 / Accepted: 20 August 2013 /

Published: 23 August 2013

\begin{abstract}
Geographical location and landforms of various types have strong effects on the developments of many cities and associated street networks. This study presents new results of landform effects, in particular the geometry of shorelines, on the grid street networks (a total of 10,442 streets) of three Brazilian coastal cities. The results are compared with the street networks of three coastal cities in Britain (a total of 22,002 streets) that have evolved through a more natural "bottom-up" process. Gibbs/Shannon entropy (a measure of dispersion) generally has a positive linear correlation with length ranges and the average lengths of the street, and for the power-law tails in particular. The geometry of the adjacent shorelines has great effect on the spatial orientation of streets in the Brazilian cities but less so for the networks of the British cities. More specifically, the more curved the shoreline, the greater is the dispersion in the street orientation and the greater the associated entropy. The results also show that the length-entropies of the outer parts of the Brazilian cities are generally lower than those of the inner parts, whereas the entropies of outer parts of the British cities are higher than those of the inner parts, indicating dispersion during streetnetwork growth in the British cities.
\end{abstract}

Keywords: size distribution; entropy; dispersion; landforms 


\section{Introduction}

Street networks of a city primarily reflect the interplay of two sets of processes, one related to human decision making, the other related to natural or geographical constraints. With regard to anthropogenic factors, some cities, or parts thereof, have developed in an essentially "bottom-up" manner through the interaction of landowners, residents and local authorities over many years. The result is a "naturally growing" city [1-4]. Other cities bear the imprint of "top-down" planning by an authorized institute or agency [4,5]. Morphological features or landforms such as shorelines, hill slopes, mountain ranges, rivers, and valleys have strong effects on the development of many cities $[1,6]$. These effects are particularly evident in the geometry of their street networks [7-9]. Of the many natural landforms that provide constraints on the morphology of cities and their street networks, coasts are arguably the most common. This is unsurprising given the historical preference for coastal locations, which include a variety of morphological features such as fjords, bays, cliffs, islands, and peninsulas.

Entropy studies have a long history in geology and geography. For example, entropy calculations have been used to model the evolution of river channels [10], transportation and trip distributions (using maximum entropy methods) [11,12], to assess city heterogeneity [13,14], to quantify urban sprawls [15-17], and as a part of "spatial entropy" measures [18]. The entropy approach used in the present paper, however, is somewhat different from those above. More specifically, entropy is used here as a measure of the probability distributions of the geometrical characteristics of two types of street networks, namely grid street networks and the more "irregular" street networks in relation to their geographical and geological constraints [9].

Brazil and Britain both provide a good opportunity for exploring the relations between shoreline morphology and the street networks of cities. More specifically, the grid street networks in Brazil and irregular networks in Britain are both constrained by the shoreline but developed as a result of completely different processes. The coastline of Brazil accommodates around $20 \%$ of the Brazilian population [19-21], a proportion that is rising rapidly because of the increasing pressure of urbanization, industrialization, and tourism [19,22]. The coastal zones of the states of Santa Catarina and Sao Paulo well illustrate the relations between fast growing coastal cities and the surrounding natural landscape $[19,23]$. By contrast, the three coastal cities in Britain date back to the $18^{\text {th }}$ and $19^{\text {th }}$ centuries and contain street networks that have thus developed over longer periods.

Clearly, the street networks in both fast growing cities, such as in Brazil, and historical cities, such as in Britain, develop in relation to specific political and socio-economic factors as well as historical and geographical restrictions [2,24-26]. While all these factors are important, the main focus in the present study is on the effects of the geographical locations of the cities, particularly the associated shoreline geometries, on the grid and irregular street networks. This paper thus compares three fast-growing cities from the southeast coast of Brazil with three more slowly evolving coastal cities from the southern part of England. The principal aim is to analyse quantitatively, primarily using an entropy method, how the curved shapes of the adjacent bays affect the shapes of cities and the geometry of their street networks. More specifically, the geometry of the street networks are analysed through a quantitative assessment of various orientation and length scaling relations and entropy measures. 


\section{Study Area}

Of the 28 metropolitan areas in Brazil, 16 are located along the coast [21]. The coastal cities have highly concentrated populations and large infrastructures which have been much affected by the speed of urbanization and activity related to tourism. The Brazilian cities selected for this study are Ubatuba and Caraguatatuba on the east coast of the state of Sao Paulo, and the city of Balneario Camboriu on the east coast of the state of Santa Catarina (Figure 1). The three coastal British cities are Southend-on-Sea, Bournemouth (both strictly towns) and Brighton and Hove, located on the southeast and south coasts of England (Figure 2). The main reasons for the selection of these cities may be summarised as follows:

- The three Brazilian cities have been growing rapidly in the last decades on account of their popularity for tourism. By contrast, the three British cities, historically very popular as resort cities, have developed over a much longer time and at different rates from the Brazilian cities. These differences, which are clearly reflected in the geometric properties of the street networks, provide unique opportunities to explore the mechanisms and constraints that affect the geometric properties of different street networks developing at different rates.

- All the cities are located at the coast and have very clear boundaries in the form of curved shorelines and a mountainous hinterland that acts to constrain their geographical expansion (Figures 1,2). The curvature varies between the shorelines, as is reflected in the differences in their radii of curvature (Figure 3 ).

- The availability of high quality Landsat images and Google-Earth views for Brazilian cities and geographic information data for British cities make it possible to digitize and carry out a detailed geographical analysis of street networks.

As regards the Brazilian cities (Figures 1,3), the city of Ubatuba is located on the coast of the state of Sao Paulo and had a population of 78,801 in 2010 [27]. The city is located between the Atlantic Ocean and largely forested and mountainous terrain to the north (Figures 1a,b and c). The city of Caraguatatuba, located on the coast of the state of Sao Paulo, is similarly constrained by the coast and the Serra do Mar Mountains (Figures 1a,b and d). The city had a population of 100,840 in 2010 [27] and is the largest city on the coast of the state of Sao Paulo. Its economy is driven by agriculture and tourism. Balneário Camboriú is a major tourist city on the coast of the state of Santa Catarina (Figures 1a,b and e). Santa Catarina has one of the highest living standards in Brazil, and is a major industrial and agricultural state. The city is bounded by hills to the north, west, and south, and constrained by the sea to the east. In 2010, the population was 108,089 [27]. To the southeast, the city margin is at the Camboriú River, which reaches the ocean at the southern edge of the city. The coastal parts of the city are characterised by tall buildings.

As regards the British cities (Figures 2,4), Southend-on-Sea is a seaside resort on southeast coast of England, on the north side of the Thames estuary. The city is one of the most popular touristic places in Britain and had a population 165,300 in 2010 [28]. The history of the city dates back to the 18th century; the city has gradually expanded since that time (Figures 2a,b). The city of Brighton and Hove is located on the south coast of England and is England's most popular seaside destination. Its history as a resort dates back to the 18th century. It gradually expanded to its present size and had a population of 258,800 in 2010 (Figures 2a,c) [28]. Bournemouth is a large resort city at the south coast of England 
with a population of 168,100 in 2010 [28]. The city history dates back to 19th century. The city is constrained by the sea to the south and the River Stour forms a natural boundary for city, to the north and east (Figures 2a,d).

Figure 1. (a) A detailed map of three coastal cities on the Atlantic coast of Brazil. Ubatuba and Caraguatuba are in the state of Sao Paulo, and Balneario Camboriu is in the state of Santa Catarina. (b) Locations of the three coastal Brazilian cities. (c) Location of Ubatuba, (d) location of Caraguatatuba, and (e) location of Balneario Camboriú (image courtesy of Google Earth) with the street networks overlaid. The rose diagrams summarise the weighted and unweighted orientations of all the streets in the networks (Section 3). Also shown are the variations in street orientation for several sub-populations. Here the sub-populations are the streets within the subareas marked by white dotted lines, namely 1-5 (Figure 1c), 1-5 (Figure 1d), and 1-3 (Figure 1e).

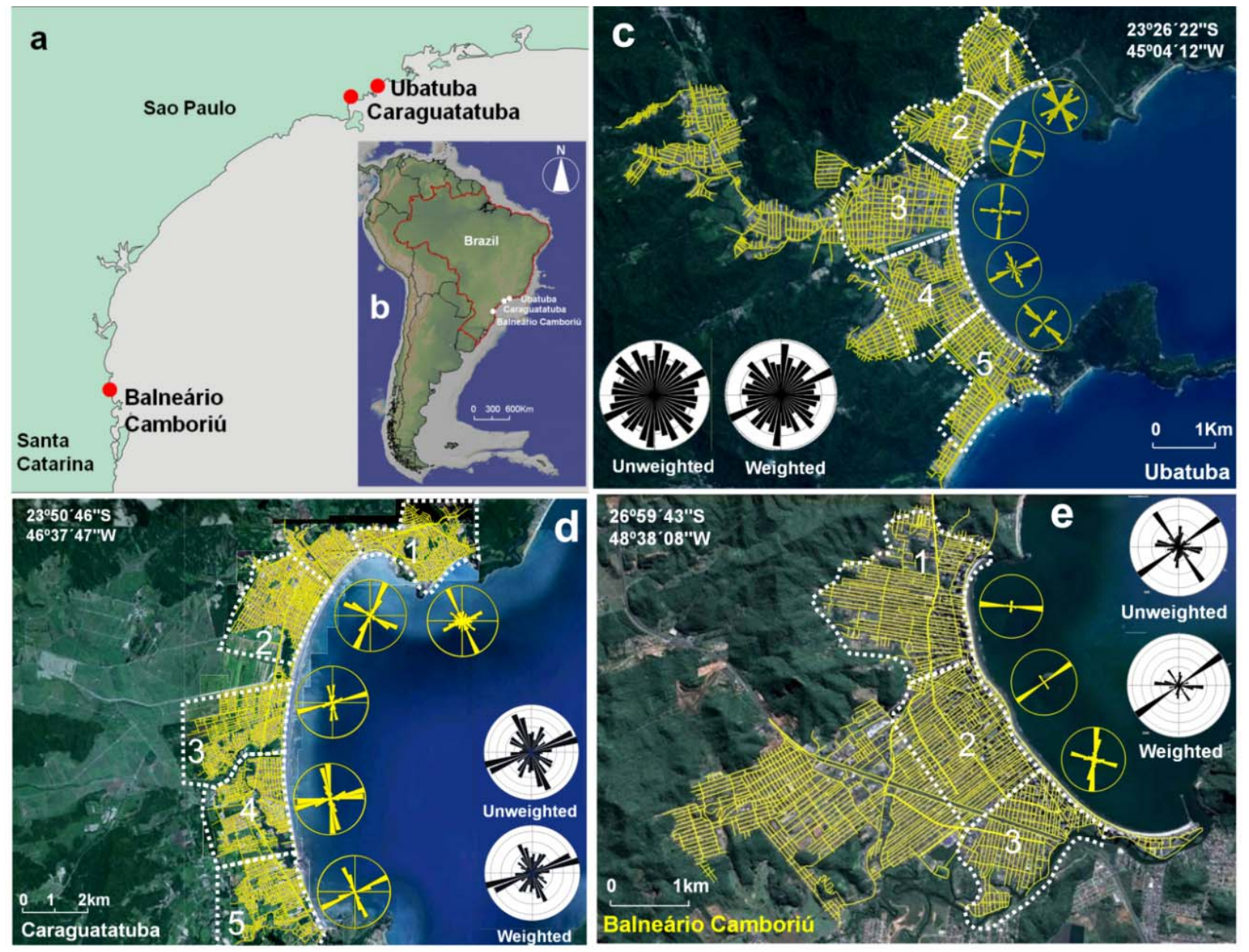


Figure 2. (a) Location map of the three coastal cities in Britain, all located in the southern part of England. Also shown are the street networks and rose diagrams (Section 3) of (b) Southend-on-Sea, (c) Brighton \& Hove, and (d) Bournemouth.
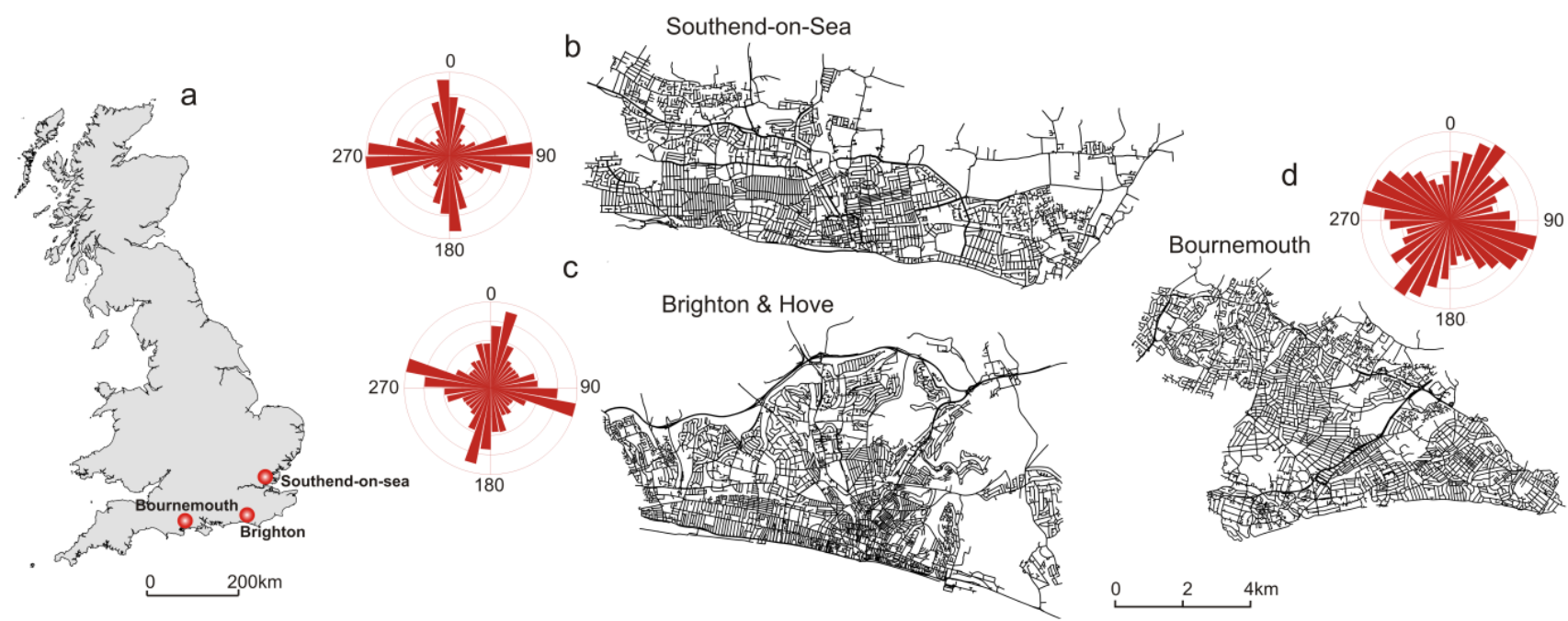

Figure 3. (a) Distributions of street orientations (histograms), number of streets, and orientation entropies [S; Equation (2)]; (b) Rose diagrams use 10 degree intervals (the width of each sector) and 0-360 degree azimuth; (c) The shoreline radius of curvature, $r$ (the arcs are indicated by red dotted lines) of the three Brazilian cities. Note that the histograms use $5^{\circ}$ as a class limit (bin width) to show the orientations of streets.
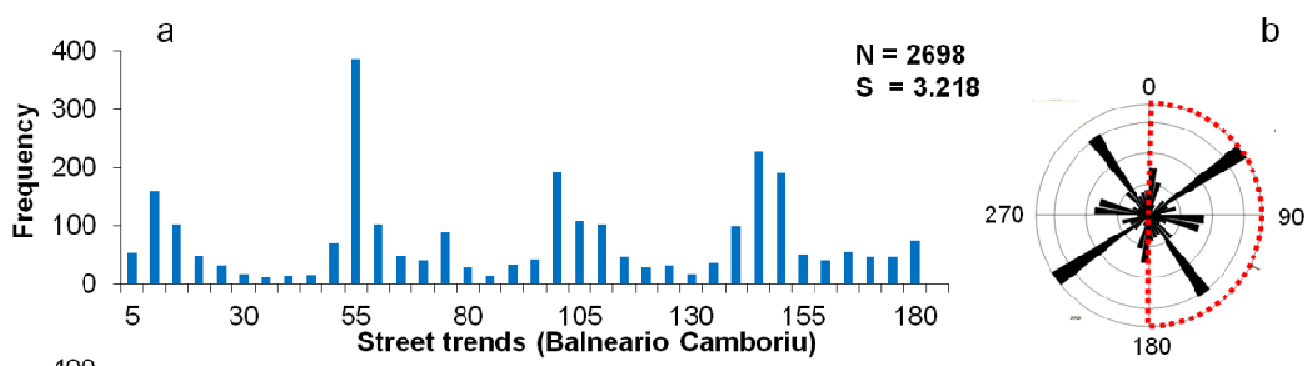

b c
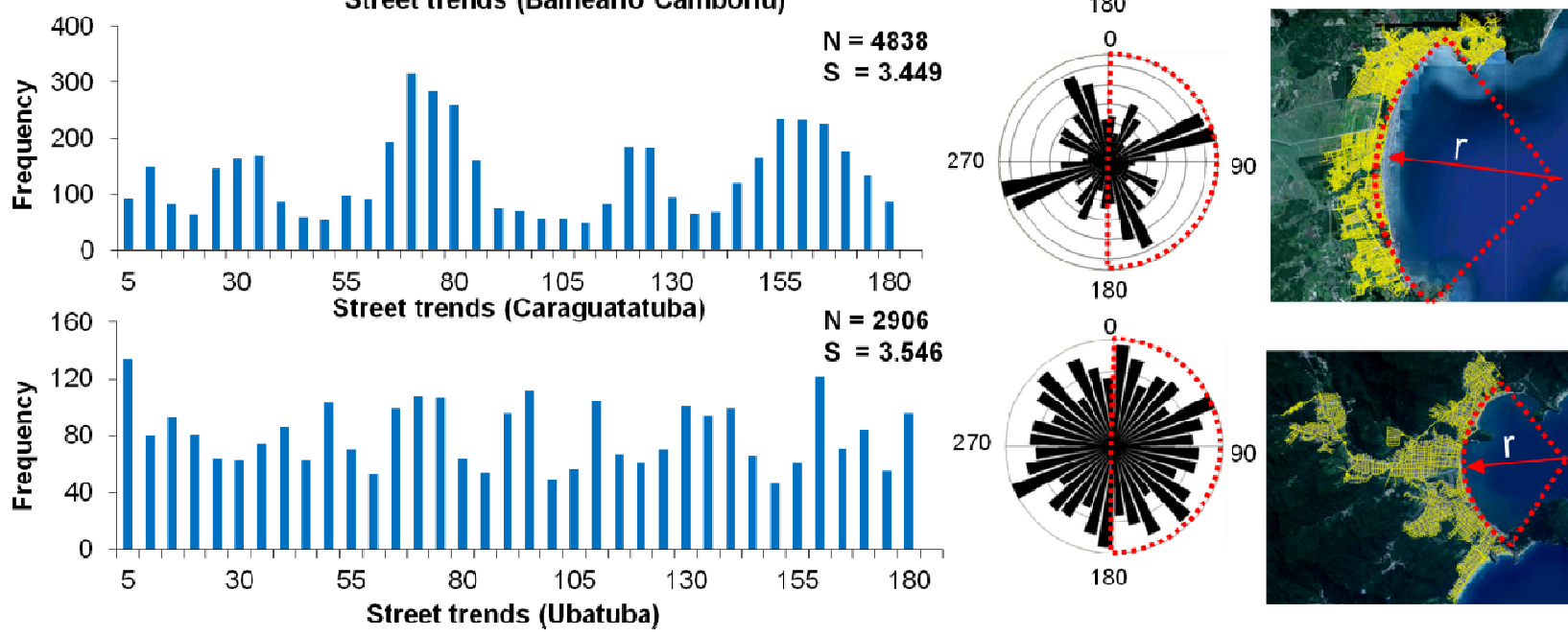
Figure 4. (a) Distributions of street orientations (histograms, using $5^{\circ}$ as a class limit for street trends), number of streets, and orientation entropies [S; Equation (2)]; (b) Rose diagrams, using $10^{\circ}$ for the width of each sector; (c) The three British cities and their shoreline radius of curvature (the arcs indicated by red dotted lines).
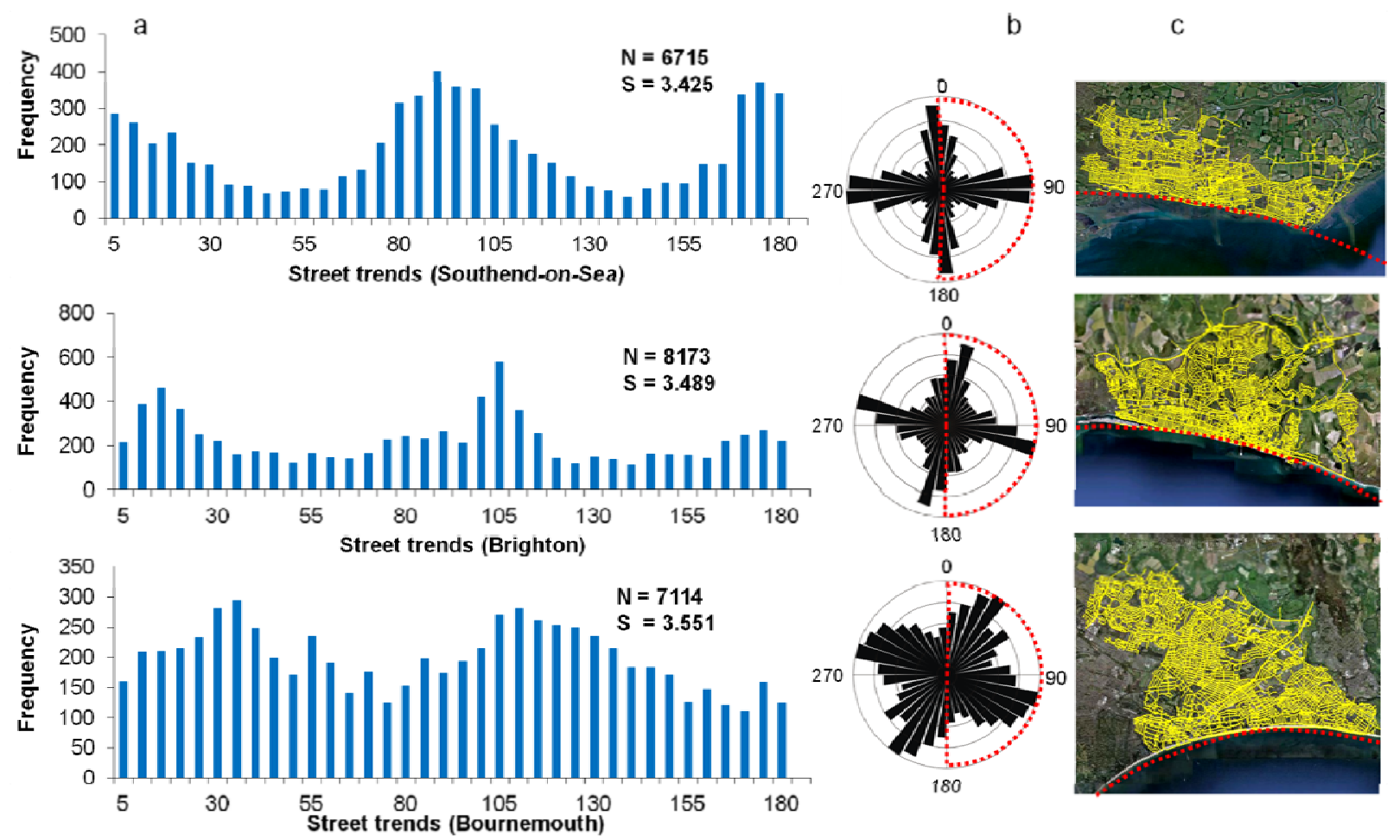

\section{Data and Methods of Analysis}

\subsection{Data}

Because of the lack of digital data, aerial photographs and high resolution satellite images were used to digitise street datasets of the three Brazilian cities. There are many websites that provide access to maps or satellite images of open source data depending on what information is needed. For the three Brazilian cities, Google Maps provide good coverage and completeness, particularly for street datasets, in comparison with other data sources such as OpenStreetMap. These can easily be compared by the visual inspection of the two data sources. There are, in addition, some studies that compare the quality of different open access data sources and their degree of accuracy [29]. As a source of the street datasets of the Brazilian cities used in this study, Google Maps are fairly accurate. Network analysis tools in a GIS environment have been used to build up the street-network datasets. The current GIS street-networks datasets and Integrated Transport Network (ITN) layers of three British cities were obtained from Ordnance Survey (OS) datasets in the UK [28] and the EDINA Digimap website [30]. Google Earth was also used for background images for each city region.

The street networks analysed here are characterised by street segments that, by definition, extend from one intersection of streets to the next one. More specifically, we represent the street networks of these cities such that intersections are nodes and streets are links between two neighbouring nodes, that is, we use a primal representation [31-34]. The data are treated as an undirected network, that is, each pair of nodes can only be connected by at most one undirected link. The geometry of a street network 
can be analysed using either the curved (real or physical) links or, alternatively, the Euclidean (straight-line) distances between the starting and end points of each street. A Euclidean analysis results in a systematic bias towards shorter link lengths [35]. In this paper, however, we use the physical links, that is, we treat curved links as curved, both as regards length and orientation.

\subsection{Directional Statistics}

Directional analysis, which is the main method for analysing the spatial orientation of streets, presents the street orientation as frequencies (Figures 3,4). The spatial orientation of a street is given as an azimuth, that is, as the angle measured clockwise between north (the reference axis) and the street. Street orientations can be represented through rose diagrams or histograms (using classes or bins). We can either use full (360 degrees) or half (180 degrees) rose diagrams for the ease of visualisation and clarity of presentation (Figures 1-4). Rose diagrams are used primarily in the earth sciences to analyse the orientation of lineaments or processes of various types [36-39]. These diagrams can be presented in various ways, but here the segments of the circles have radii that are proportional to the frequency. This presentation visually emphasises high-frequency orientation, which other presentations (such as kite roses) do not $[38,40]$.

Lineaments can be presented either as directional or oriented data. In directional data we can distinguish one end of the lineament from the other, or north from south, or left from right, providing unidirectional or asymmetric roses. Streets, and many geological lineaments, are oriented data, that is, they have no directional distinction and yield bidirectional or symmetric roses (Figures 2-4) so that the opposite classes or sections ( $180^{\circ}$ apart) have the same frequency [38]. The rose diagrams presented in this paper were created using the GEOrient software [41]. For each dataset, two types of analyses were undertaken. The first uses non-normalised or unweighted data, that is, azimuth data without considering the lengths of streets, and where short streets and long streets have equal weight in the diagrams. The second type uses azimuth data that are normalised or weighted by the length of the shortest street, in which case more weight is given to the long streets because they consist of many short segments.

\subsection{Street Length Distribution}

Numerous natural (both physical and biological) and anthropogenic phenomena have been modelled with reference to heavy-tailed or power-law distributions [32,42-44]. For a cumulative frequency distribution, a power law has the form:

$$
P(\geq x)=C x^{-D}
$$

where $P(\geq x)$ is the number of values larger than or equal to $x, \mathrm{C}$ is a constant of proportionality, and $\mathrm{D}$ is the scaling exponent (Figure 5). If the frequency distribution is transformed into a probability distribution, $P(\geq x)$ indicates the probability of a random variable realising a value larger than or equal to $\mathrm{x}$. Power laws are scale invariant. This means that there are no objects or processes described by a power law that are typical for the distribution as a whole. Power laws are widely thought to arise from "preferential attachment" or other forms of interdependence among objects in contrast to normal distributions $[45,46]$, which are more common among independent objects. If plotting the logarithms of the value $(x)$ and its probability $\mathrm{P}(x)$, namely $\log (\mathrm{P}(x))=\log (\mathrm{C})-\mathrm{D} \log (x)$, known as a 
bi-logarithmic or log-log plot, yields a straight line (Figure 5), the distribution is generally considered to fit a power law [44].

Figure 5. Frequency distributions of the lengths of all street segments measured in Ubatuba $(\mathrm{N}=2,906)$, Carauatatuba $(4,838)$, and Balneario Camboriú $(2,698)$. (a) Ordinary cumulative length distribution; (b) log-log plots showing two different scaling regimes, that is, different scaling exponents, D1 and D2, indicating different (short and long) street populations. Minimum street lengths are $9 \mathrm{~m}$ for Ubatuba and Caragutatuba and $6 \mathrm{~m}$ for Balneario Camboriú (Table 1); because of the scale, these minimum lengths appear here as $0 \mathrm{~m}$.

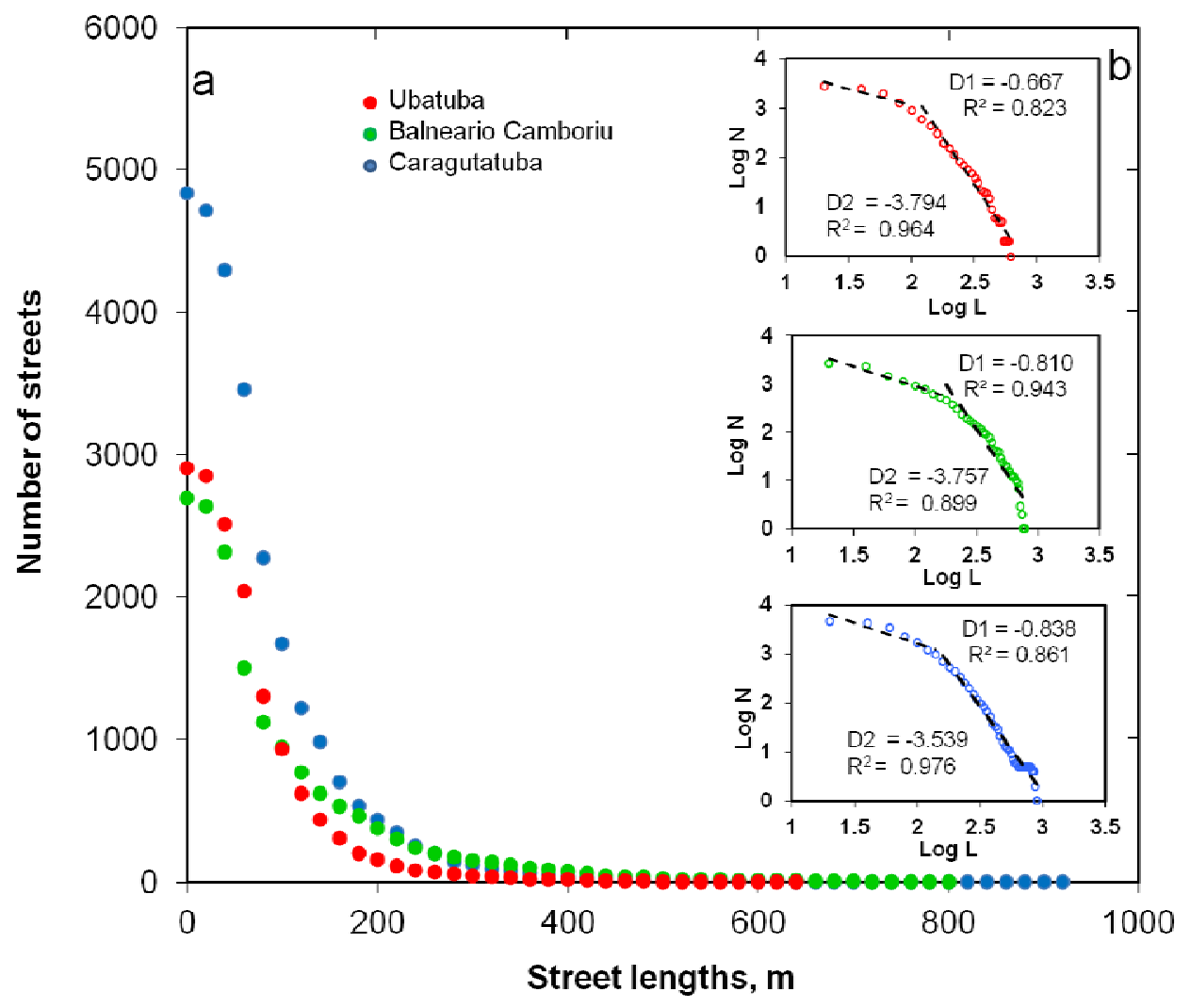

We use a cumulative distribution function, rather than a probability density function (histogram), for the power-law models. This we do partly because the visual form of a cumulative distribution function is more robust - particularly against fluctuations related to finite-size samples in the tail of the distribution - than of a conventional probability density function [46].

More rigorous tests (beyond the scope of this paper) can be made to compare the power-law fit of the data distribution with its fit to other functions or models [46]; such tests have been applied to street populations by Mohajeri et al. [9]. Even if alternative models (log-normal, exponential, stretched exponential etc.) may statistically fit some of the street network datasets better than a power law, power-law fits are still useful in the present context because they provide a convenient basis for distinguishing between street populations (of different lengths and functionality) based on their length ranges and average lengths which, in turn, can be compared with calculated entropies. Also, when using methods such as the maximum likelihood estimate for testing the appropriateness of power-law models $[32,46]$ it is generally difficult to decide between log-normal and the power-law models because, for realistic ranges of $\mathrm{x}$, the two models are very similar. Commonly, the decision whether to 
use a power law or an alternative model does not only depend on how well the models fit the data but also on the likely physical basis or theoretical factors that generate, or contribute to the generation of, the data and the scientific aims of the study [46-48].

There are commonly one or more breaks in the log-log plot, yielding multiple straight lines with different slopes, suggesting that the data can be divided into sub-populations rather than treated as a single population [49]. The straight-line slopes on the log-log plots represent different scaling regimes which may not necessarily follow power laws. However, they can be used to distinguish between the different street populations (Figure 5).

\subsection{Entropy Analysis}

Entropy is of fundamental importance in thermodynamics, statistical mechanics, engineering, biology, information theory, and many other fields [50-54]. The Gibbs/Shannon entropy S for a general probability distribution is given as:

$$
S=-k \sum_{i=1}^{t} p_{i} \ln p_{i}
$$

where $t$ is the number of classes or bins that contain streets (length or orientation) in the frequency distribution (the number of bins with nonzero probabilities of streets, the bins having a fixed width) and $p_{i}$ is the frequency or probability of streets belonging to or falling in the $\mathrm{i}$-th bin, that is, the probability of the i-th class or bin. For Shannon's entropy, used in information theory, the constant $\mathrm{k}$ in Equation (2) is given in units of bit or nat (depending on the base of the logarithm used) whereas for Gibbs (and, originally, for Clausius) entropy, used in statistical mechanics, $\mathrm{k}$ is given in $\mathrm{J} \mathrm{K}^{-1}$ or other units suitable for Boltzmann's constant, $\mathrm{k}_{\mathrm{B}}$. When calculating entropy using Equation (2), only the bins with at least one measured (orientation or length of a) street are included. By definition, the sum of the probabilities of all the bins is equal to one, so that:

$$
\sum_{i=1}^{t} p_{i}=1
$$

Since the probabilities are always between 0 and 1 [Equation (3)], while the natural logarithms of numbers between 0 and 1 are negative, the minus sign in Equation (2) is to make sure that the entropy value is positive. Here the probabilities are a measure of the chance of the orientation or length of a randomly selected street from the population falling in a certain bin. Entropy is also directly connected with uncertainty: the greater the entropy, the greater the uncertainty. As discussed below, the entropy as calculated by Equation (2) reaches its maximum when the distribution is uniform; this distribution is also the one with the greatest uncertainty as to the likely outcome.

\section{Results}

The street networks of the six coastal cities show many similarities but also certain dissimilarities (Figures 1-4,6-7). The similarities include street numbers in the range of about 3,000-8,000, and city populations in the range of about 80,000-260,000 (Table 1). The Brazilian cites have grid-based street networks [55] whereas the British cities have irregular networks that are the results of more protracted natural or organic growth. The landscape constraints, in particular the radii of curvature of shorelines, 
are also very different between the British and the Brazilian cities (Figures 3,4; Table 1). Here we analyse and compare all the six cities as regards street orientation, lengths, and associated entropies in relation to landscape constraints.

Table 1. Number of streets, radius of curvature $(\mathrm{km})$, scaling exponent, lower bound $\left(\mathrm{x}_{\mathrm{min}}\right)$ at which the power law no longer applies based on the maximum likelihood estimation $[9,46]$, orientation entropy, length range $(\mathrm{m})$, average length $(\mathrm{m})$ of all the street populations (and sub-populations, marked $a$ and $b$ ) for the six cities, and length entropy. Sub-populations $b$ (in bold) are the power-law tails.

\begin{tabular}{|c|c|c|c|c|c|c|c|c|}
\hline City & $\begin{array}{l}\text { Number } \\
\text { of streets }\end{array}$ & $\begin{array}{l}\text { Radius of } \\
\text { curvature }\end{array}$ & $\begin{array}{c}\text { Scaling } \\
\text { exponent }\end{array}$ & $\mathbf{X}_{\min }$ & $\begin{array}{c}\text { Orientation } \\
\text { entropy }\end{array}$ & $\begin{array}{c}\text { Length } \\
\text { range } \\
\end{array}$ & $\begin{array}{c}\text { Average } \\
\text { length }\end{array}$ & $\begin{array}{l}\text { Length } \\
\text { entropy }\end{array}$ \\
\hline Ubatuba & 2906 & 2.35 & 2.605 & $106 \pm 6$ & 3.546 & $9-624(615)$ & 92 & 2.237 \\
\hline $\mathrm{a}$ & - & - & 0.667 & - & - & $9-100(91)$ & 61 & 1.721 \\
\hline $\mathrm{b}$ & - & - & 3.794 & - & - & $\begin{array}{c}100-624 \\
(524) \\
\end{array}$ & 159 & 2.282 \\
\hline Caraguatatuba & 4838 & 9.3 & 2.583 & $146 \pm 25$ & 3.449 & 9-901 (892) & 101 & 2.389 \\
\hline $\mathrm{a}$ & - & - & 0.838 & - & - & $9-140(131)$ & 72 & 1.943 \\
\hline $\mathrm{b}$ & - & - & 3.539 & - & - & $\begin{array}{c}140-901 \\
(761)\end{array}$ & 217 & 2.523 \\
\hline $\begin{array}{l}\text { Balneario } \\
\text { Camboriu }\end{array}$ & 2698 & 3.74 & 2.18 & $164 \pm 57$ & 3.218 & $6-794(788)$ & 109 & 2.632 \\
\hline $\mathrm{a}$ & - & - & 0.81 & - & - & $6-160(154)$ & 68 & 2.041 \\
\hline $\mathrm{b}$ & - & - & 3.757 & - & - & $\begin{array}{c}160-794 \\
(634)\end{array}$ & 275 & 2.753 \\
\hline $\begin{array}{c}\text { Southend-on- } \\
\text { Sea }\end{array}$ & 6715 & 39 & 2.366 & $157 \pm 63$ & 3.425 & $\begin{array}{l}4-1651 \\
(1647)\end{array}$ & 86 & 2.568 \\
\hline $\mathrm{a}$ & - & - & 0.872 & - & - & $4-160(156)$ & 56 & 2.003 \\
\hline $\mathrm{b}$ & - & - & 2.875 & - & - & $\begin{array}{c}160-1651 \\
(1491) \\
\end{array}$ & 273 & 2.969 \\
\hline $\begin{array}{l}\text { Brighton \& } \\
\text { Hove }\end{array}$ & 8173 & 30 & 2.15 & $150 \pm 30$ & 3.489 & $\begin{array}{l}4-1869 \\
(1865)\end{array}$ & 87 & 2.658 \\
\hline $\mathrm{a}$ & - & - & 0.763 & - & - & $4-120(116)$ & 48 & 1.814 \\
\hline $\mathrm{b}$ & - & - & 2.515 & - & - & $\begin{array}{c}120-1869 \\
(1749) \\
\end{array}$ & 234 & 3.184 \\
\hline Bournemouth & 7114 & 12 & 2.515 & $142 \pm 40$ & 3.551 & 4-952 (948) & 82 & 2.395 \\
\hline $\mathrm{a}$ & - & - & 0.881 & - & - & $4-140(136)$ & 55 & 1.906 \\
\hline $\mathrm{b}$ & - & - & 3.518 & - & - & $\begin{array}{c}140-952 \\
(812)\end{array}$ & 230 & 2.658 \\
\hline
\end{tabular}

\subsection{Street Trends}

As regards the Brazilian cities, Balneario Camboriú has a clear orthogonal orientation, whereas Caraguatatuba and, especially, Ubatuba exhibit greater directional dispersion or spread. Despite the imposed grid network, the landscape constraints, and in particular variation in shoreline alignment, 
result in the orientations of the streets generally changing gradually - but in some parts somewhat abruptly - between different parts of the cities (Figure 1).

For Balneario Camboriú one of the main street orientations is perpendicular to the shore, whereas the other main orientation is parallel to the shore (Figures 1e,3). Comparison of the weighted and unweighted street orientations (Figure 1e) shows that the shore-perpendicular streets tend to be longer than shore-parallel streets. Away from the shoreline, the street orientation follows the orientation of the valleys. The streets in the southernmost part of the city (sub-population 3) have orientations partly controlled by the shoreline and partly by a river. The main street orientation is highly oblique to the shoreline (and to the river) and is close to north-south. Interestingly, minor orientation in this area is not quite orthogonal to major one and is west-northwest. The dispersion in the orientation of streets in Caraguatatuba is greater than in Balneario Camboriú (Figure 1d), reflecting, again, primarily the planform of the shoreline. Streets follow the shoreline geometry, spread out from the shore into the wide valley while preserving their original grid configuration, and can be divided in five sub-populations. The spread in the orientation of streets in Ubatuba (Figure 1c) is even greater and, again, is largely due to the radius of curvature of shoreline but partly to the shape and orientation of the main valley within which the city is located. The shoreline is more indented and comprised of two adjacent bays, giving rise to five sub-populations. Also, the main valley within which a part of Utatuba is located changes its orientation abruptly from east-west to northwest, and the street orientations change accordingly.

The directions of the orthogonal streets tend to vary gradually along the coast. This was explored in greater detail by dividing the cities into sub-populations and showing how the two orthogonal street orientations change along the city so that one of the orientations is always roughly perpendicular and the other roughly parallel to the crescent city axis (Figurea 1c,d and e). The sub-populations were chosen using the following criteria: (1) the number of streets should be similar in all the sub-populations within each city; (2) the sub-populations should cover similar areas; and (3) the sub-populations should reflect the variation in the alignment of the shoreline.

The shorelines of the British cities have much larger radii of curvature than those of the Brazilian cities (Figures 1,2; Table 1). Yet, their orientation variations, as reflected in the rose diagrams (Figures 2,4), are generally similar to those of the Brazilian cities (Figures 1,3). The Brazilian streets are, on average, longer than the British streets (Table 1), but the great spread in spatial orientation of the streets of the Brazilian cities is mostly attributable to their highly curved shorelines (Figures 1,3). By contrast the shorelines of the British cities are comparatively straight (large radii of curvature), but there the variation in orientation due to their natural or organic style of development.

Additional quantitative arguments supporting the effects of the curved shorelines on the dispersion in street orientations are provided through considerations of entropy. Equation (2) was used to calculate the orientation entropy, that is, the entropy of the street-orientation distribution. The probability $p_{i}$ in Equation (2) is then the likelihood of street orientations belonging to or falling in the $i$-th bin. The results (Figures 3,4; Table 1) show that, of the Brazilian cities, the entropy is lowest in the Balneario Camboriú, where the street patterns have the least spread, and higher in Caraguatatuba and Ubatuba, where spread is greater. The spread is partly inversely related to the radius of curvature of the shoreline (Figure 3). The British cities generally show similar orientation entropies as the Brazilian ones; the great dispersion of the street networks of the British cities being related to their natural growth. The variation in entropy is necessarily small-much smaller than for length distributions (Section 4.2)-because the 
number of bins is fixed for all the distributions at (a maximum of) 36 (each bin having the class width of $5^{\circ}$ ). What the results show very clearly, however, is that the greater the landform constraints, here primarily the curvature of the adjacent shoreline, the greater is the dispersion in orientation of streets, and the greater is the orientation entropy.

These results can now be put into the context of general entropy considerations. When a statistical distribution becomes more uniform, the entropy associated with that distribution increases [50-54]. In case the distribution is perfectly uniform, all the bins have the same frequency and the entropy reaches its maximum. For a perfectly uniform distribution Equation (2) reduces to the well-known Boltzmann's equation:

$$
S=k \ln t
$$

where $t$ is the number of bins. How closely a statistical distribution approaches uniformity is readily visualised using histograms (Figures 3,4). Whereas Balneario Camboriú has a few clear orientation peaks, and very few streets that fall in bins between the main peaks, all the other five cities have much more uniform distributions. The most uniform distributions are for Ubatuba and Bournemouth, which also have the two highest orientation entropies.

\subsection{Street Lengths}

Log-log plots of the street-length data show that all the datasets are better fitted by two straight lines (Figure 5) with different slopes than with a single line. The different slopes indicate different scaling regimes (Equation 1) and represent different street populations; small scaling exponents represent short streets and large scaling exponents long streets. The crossing points for discriminating between short and long streets have been estimated in two different ways, namely (1) through visual inspection based on the line-fitting procedure, and (2) by using the maximum likelihood estimation for the exact point locations $[9,46]$ - shown as $X_{\min }$ in Table 1. Also, the ranges for the lower bounds $\left(X_{\min }\right)$, namely the bounds at which the power law no longer applies, are given in Table 1 for all the studied cities. The calculated $\mathrm{X}_{\min }$ values are generally similar to those obtained from visual inspection (see the length ranges in Table 1).

For each city, we distinguish between three main populations based on their scaling exponents. The first, marked by a (Table 1), contains short (local) streets and has a small scaling exponent. The second, marked by b (Table 1), contains long streets (collectors and arterials) and has a large scaling exponent. The third, unmarked, contains all the streets in the city, and has a scaling exponent somewhere between that of the short and the long streets taken separately. The street length range, the average length, and the length entropy were calculated for each sub-population for all the studied cities (Table 1). Equation (2) was used to calculate the length entropy, that is, the entropies of the cumulative distributions of street length. $p_{i}$ in Equation (2) is the probability of a street length belonging to the i-th bin. In order to compare the entropy between cities, all the bins used are of equal size (width), that is, $20 \mathrm{~m}$. The total population contains sub-populations a and $\mathrm{b}$ (Table 1).

When plotting the entropies against the length ranges and average lengths within each city for sub-populations "a" and "b" (short and long streets), the result show generally strong linear correlations (Figures $6 \mathrm{a}-\mathrm{d}$ ). It follows that much of the variation in entropy between the street-length distributions can be explained in terms of variation in street length ranges and average lengths. More 
specifically, from the values of the coefficient of determination, $\mathrm{R}^{2}$ (Figures $6 \mathrm{a}-\mathrm{d}$ ), it follows that some $84 \%-97 \%$ of the variation in entropy can be explained in terms of variation in length range, and $91 \%-94 \%$ in terms of average length. The strong correlations, as well as the low p values, for the relations between entropy and length range, and between entropy and average length (Figures 6a-d) indicate that these findings are statistically significant $[56,57]$.

Figure 6. (a,c) Entropy versus the length range, and entropy versus average length; (b,d) of the sub-populations marked by "a" and "b" in Table 1. p-values show the significance of $\mathrm{R}^{2}$ for each linear correlation; (e,f) Entropy versus the average length and length range only for sub-populations marked by "b", that is power-law tails, in Table 1.
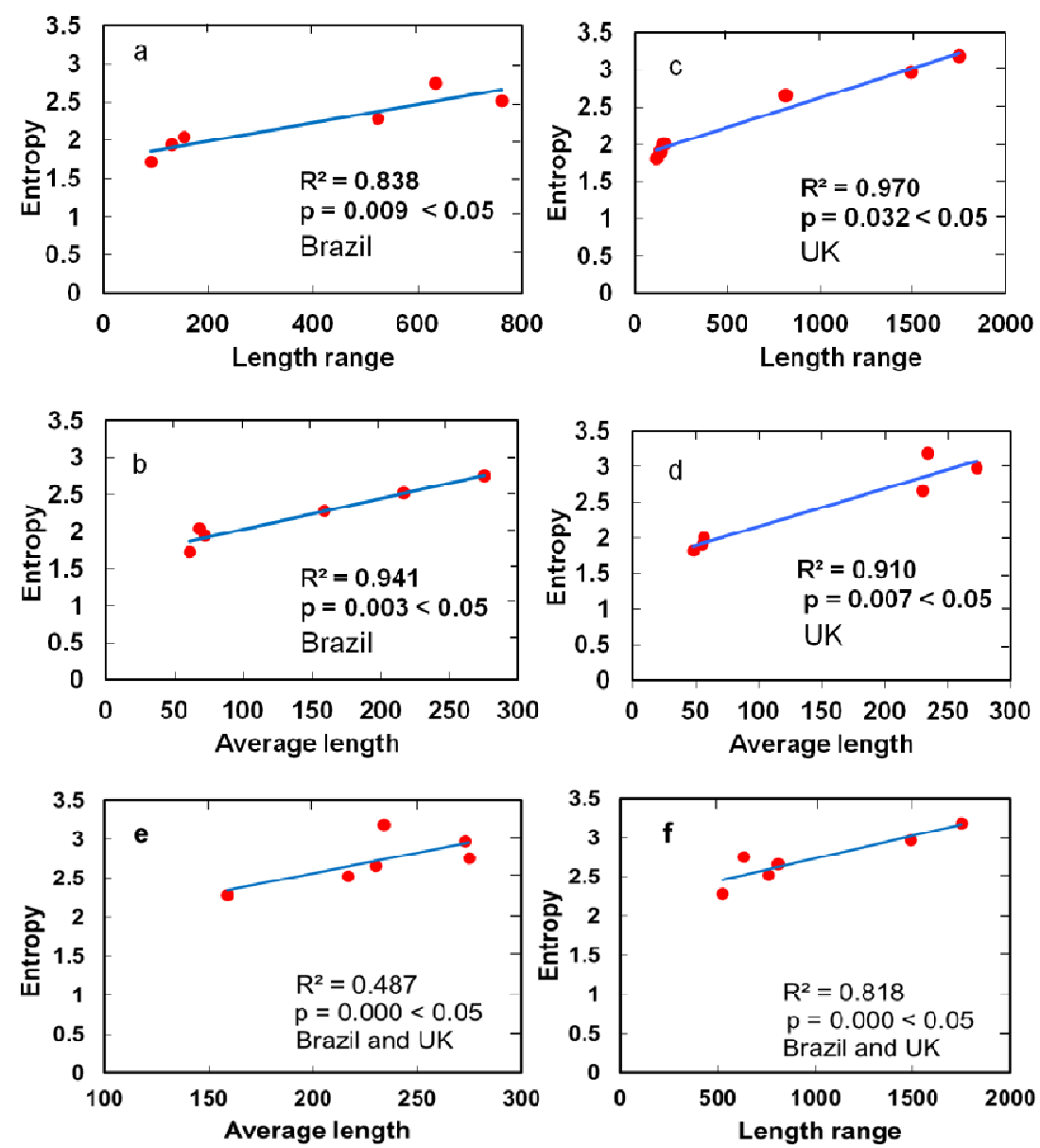

While the correlations are clear and significant, the long and short streets belong to different scaling regimes and have different functionality. There may also be some doubt as to the shorter streets strictly following power-law distributions, given that their length ranges are small. To explore the above correlations further, we also tested the correlations only for the long streets, thereby avoiding the mixture (joint correlations) of short and long streets and potential "clustering" effects. When plotting the average lengths and the length ranges for long streets (sub-populations "b") against entropy, we again get reasonable to high correlations (Figures 6e,f). In particular, there is a fair correlation between entropy and average length and a high correlation between entropy and length range. The results imply that $49 \%-82 \%$ of the variation in entropy of the long streets can be explained in terms of variation in 
street length. The sample sizes, however, are small, and further exploration, using larger datasets, are needed to establish (or refute) these correlations as general rules.

\section{Discussion}

The results presented here show that shoreline geometry can have large effects on the general shape of a coastal city and the configuration of street networks [9]. In all the studied cities, street orientations and lengths are, to a large degree, controlled by the shoreline that functions as their boundary, but more so for the Brazilian than the British cities (Figures 1-4). The entropies of the street orientations show a clear correlation with the orientation distributions: where the orientation is peaked, as for Balneario Camboriú, the entropy is low, but as the orientation distribution becomes more uniform the entropy increases (Figures 3,4; Table 1). The landscape constraints, particularly the radius of curvature of the shorelines affect the orientation distributions or dispersion, particularly of the grid-based fast growing cities of Brazil (Figure 3).

There are some important differences in the length ranges of the street populations. On log-log plots, all the street populations show breaks in the straight-line slopes, that is, abrupt changes in the scaling exponents at lengths from 100 to $160 \mathrm{~m}$ (Figure 5; Tables 1). The shorter streets are mainly local streets whereas the longer ones are collectors and arterials. The main exception as regards many of the correlations obtained here is Balnerio Comboriú (Figures 1,3). Its long streets extend into the main valley and are perpendicular to the shoreline, broadly similar to that of the other cities. The difference is, however, that in Balnerio Comboriú there are very few shore-parallel streets that intersect the shore-perpendicular streets. Since a street length is the distance from one intersection to the next one, it follows that the streets of Balnerio Comboriú, particularly the short ones, are unusually long (Table 1). To explore the relations between street lengths and street orientations, street orientation frequencies, and maximum street lengths were plotted against street orientations (Figure 7).

As regards the Brazilian cities, the network of Ubatuba (Figure 7a) shows great variations in the maximum length of the streets between bins, but there is not much correlation between these and the orientation variations. In particular, the orientation is close to uniform, as is also seen in Figure 3. By contrast, both Caraguatatuba and Balnerio Comboriú show clear correlations between the maximum street lengths and the orientation frequencies (Figures $7 \mathrm{~b}, \mathrm{c}$ ). For these two cities, it is clear that the orientation frequency distribution is much more peaked (and the entropy thus lower, Table 1) than in the case of Ubatuba, and also that the maximum lengths of the streets fall roughly in the peaked bins. For the British cities (Figures $7 \mathrm{~d}$,e and f) the results do not show much correlation between the maximum street length and the orientation frequency, again reflecting the natural growth of these cities.

For the grid-networks in Caraguatatuba and Balnerio Comboriú the results suggest that where the street orientation peaks (where the network has preferred (orthogonal) directions), the longest streets tend to coincide with the peaks. This means that only streets along the main orthogonal directions attain great lengths; streets with other orientations are primarily for forming interconnections between the longer streets and thus remain short. For irregular networks, such as those of the British cities, no such correlations are expected or, indeed, observed. 
Figure 7. Relation between the maximum street lengths (upper curves marked in red) and the street orientations (lower curves marked in blue) for the six coastal cities.
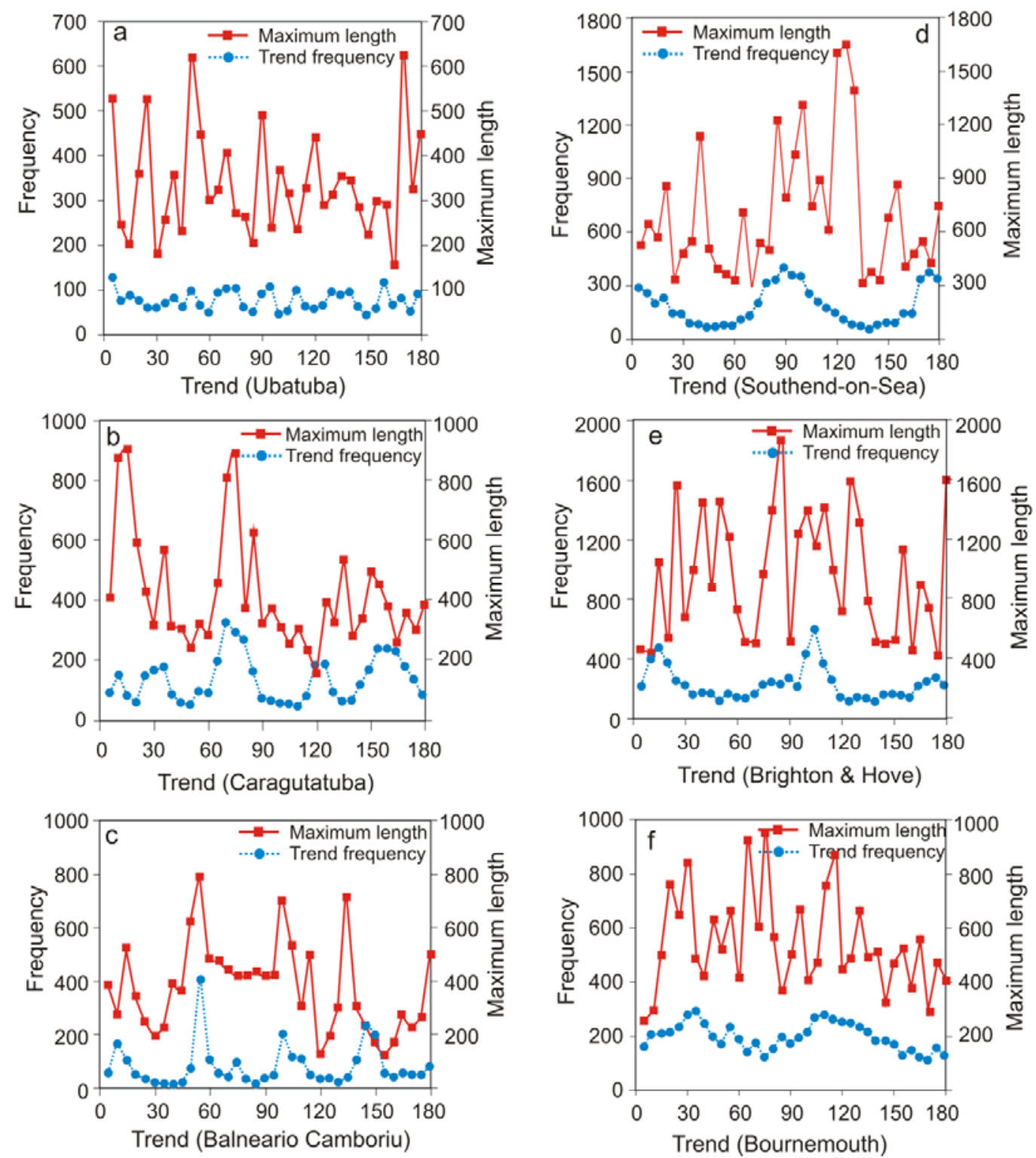

Entropy can be interpreted as a measure of "missing information" or "degree of uncertainty" [58-60]. Generally, for both Brazilian and British cities, the uncertainty as to the future development of the street network, as well as the length and orientation of a randomly selected street from the present network, is related to the entropies of the street lengths and orientations. In the studied cities, the greatest uncertainty as to the orientation of future streets is in the networks of Ubatuba and Bournemouth, whereas the greatest uncertainty as regards the length of future streets is in networks of Balneario Camboriu and Brighton and Hove, both uncertainties being reflected in the associated orientation and length entropies (Table 1).

The effect of the curvature of the shorelines on the geometries of the street networks is very noticeable (Figures 1-4). It is clear that one of the main street orientations is mostly roughly perpendicular and the other roughly parallel to the shoreline. This applies to all the Brazilian cities and to the parts of the British cities that are close to the shore. More specifically, the correlation between shoreline curvature and the network geometries is particularly clear for Ubatuba, Caraguatatuba, and 
Balneario Camboriú but also, to a lesser degree, for Southend-on-Sea and Brighton and Hove. Bournemouth extends far inland and, there, the directions of the hills and valleys affect street orientations. The same could be said of Balneario Camboriú, in that it extends quite far inland. However, Balneario Camboriú generally maintains similar street orientations inland as it does closer to the coast. This is primarily because the inland valleys and hills have orientations that are mostly either perpendicular or, more commonly, parallel with the shoreline.

The importance of shoreline orientation as regards network geometry can be also related to the way that a city evolves. For some of the British cities, the street network gradually expanded inland from a nucleus, the initial village, which may be a natural harbour $[9,61]$. If the network remained unchanged as regards range in street length, then the scaling exponent of the long streets and the entropy would have remained the same [9,61]. If, however, the short streets maintained their lengths as the city expanded while the maximum lengths of the long streets (and thus their average lengths) increased, the entropy would have increased during the city evolution [9]. In some coastal cities [9,61], however, only the most "favourably oriented" (i.e. coast-parallel) streets, have a chance of becoming long as the city expands [61]. This can be related to many parameters including the street functionality within the city, the city shape, and the geographical location.

To explore further the similarities and differences between the street networks, we calculated the street-length entropies of the inner part and selected outer parts for all the six cities and compared them with the corresponding average street lengths (Figure 8). For British cities, the inner part is defined primarily by its being older and commonly surrounded by "ring roads" (beltways or loops). For the Brazilian cities, the inner part constitutes the "downtown" part. The number of streets in the inner part varies between cities, simply because the cities themselves are different in size. Thus, for the present comparison, an outer part with roughly the same number of streets as in the inner part was selected as far from the city centre as possible.

The results show that the length-entropies of street networks in the inner parts of the three cities in Brazil are higher than their outer parts [Figure 8(a)]. By contrast, the length-entropies of the inner parts of the British networks have either equal or significantly lower entropies than those of the outer parts. These differences, to a degree, reflect the geometric differences between the grid networks of the Brazilian cities and the irregular networks of the British cities. The differences between length-entropies of the streets in the inner and outer parts are also reflected in the different average lengths of the streets in these parts in relation to surrounding landscapes [Figure 8(b)]. While the inner parts of cities in Brazil have higher average lengths (from 103 to $111 \mathrm{~m}$ ) than their outer parts (from 85 to $102 \mathrm{~m}$ ), the inner parts of British cities have lower average lengths (from 59 to $70 \mathrm{~m}$ ) than their outer parts (from 78 to $89 \mathrm{~m}$ ). As indicated above (Figure 6) the length entropies are directly related to the average street lengths; as the average length increases so does the entropy. 
Figure 8. (a) Length-entropy and (b) average length for the inner and outer parts of six street networks in Brazil and Britain.

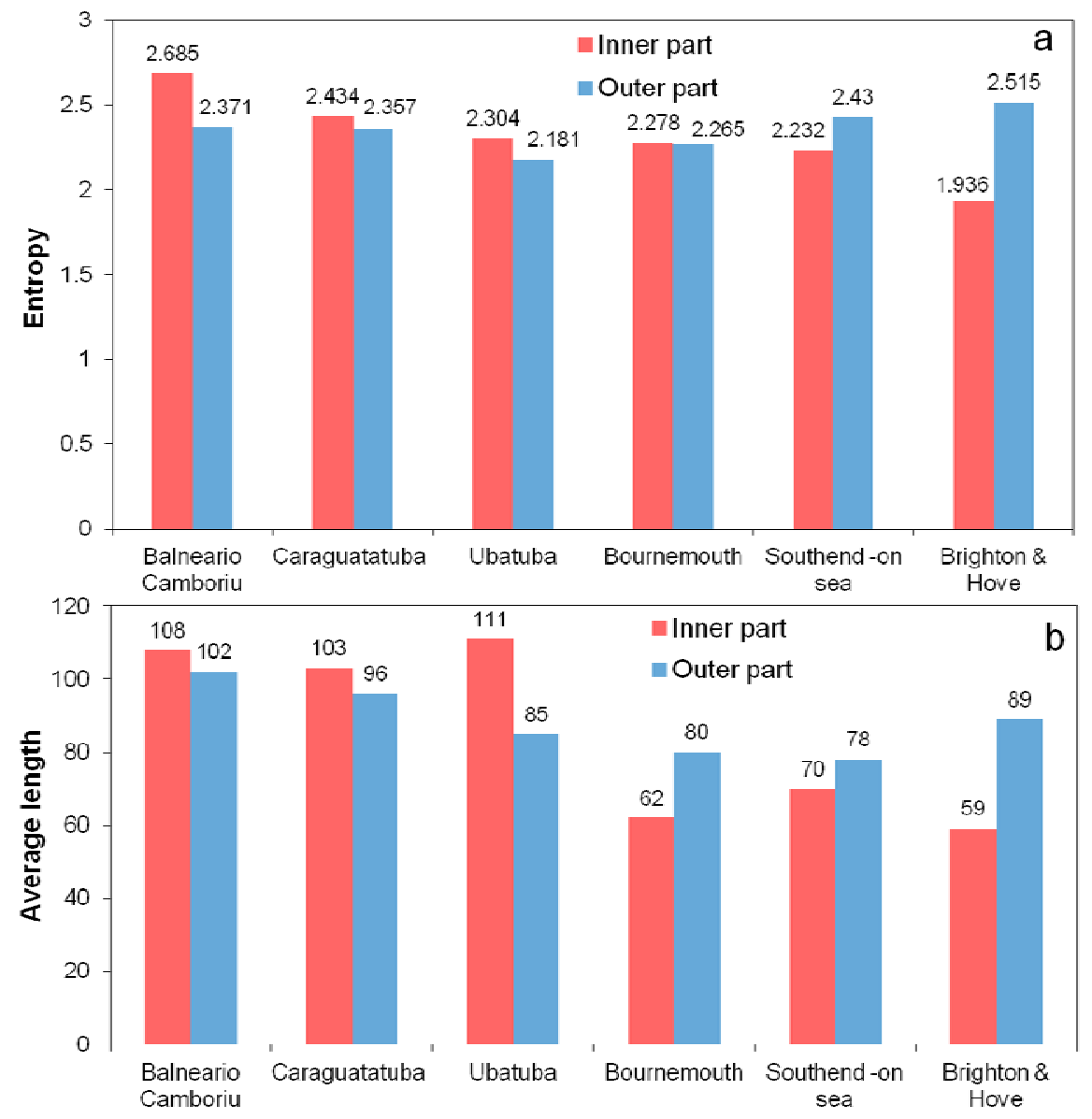

The differences in entropy and average street length between the Brazilian and British cities can also be related to landscape constraints. The Brazilian cities are constrained by the shoreline on one side and by steep hills and mountains on the other side [cf. Figures 1(c,e)]. The hills and mountains (and associated valleys) restrict the growth of the Brazilian cities, and thereby the lengths (and length-entropies) of the street networks in the outer (here the inland) parts. The street networks in British cities are also controlled by the shoreline on one side, but they are essentially free to expand into the land since there are no significant mountains or valleys that restrict their inland growth. When the Brazilian cities grow inland, the space restrictions force the streets to become shorter so that their average length and length-entropy decrease. By contrast, the street networks of the British cities face no such morphological constraints, so that their networks tend to expand (increase their length-entropies, or disperse) as they grow inland [9].

\section{Conclusions}

In this paper, the effects of shoreline geometry on the street networks of six coastal cities in Brazil and Britain are analysed. The results, at this stage and for these cities, indicate that the curvature of the shoreline is a major landscape feature that has strong control on the overall geometry of the street networks, particularly for grid networks and close to the shoreline. For naturally grown cities, such as the British ones, and for cities whose street networks extend far inland, where valleys and hills affect street orientations and lengths, the shoreline effects become less dominating. The results also suggest 
that the street lengths and orientations and associated entropies of the studied cities are strongly affected by the surrounding landscape. Comparing the inner and outer parts of the cities shows that the length entropies are mostly controlled by the space available for the network growth. Thus, the networks of Brazilian cities, whose inland growth is restricted by morphological constrains such as hills, mountains, and valleys, have lower length-entropies and average lengths in their outer (inland) parts than in their inner (coastal) parts. By contrast, the networks of the British cities face no inland morphological constraints - are free to expand - and have larger length-entropies and average lengths in their outer (inland) parts.

The results presented here, however, reflect the short-term state of the coastal cities and associated street networks. In a future development of the present work, the long-term evolution of the street network over hundreds of years will be explored, including the variation in parameters such as entropy, street-network density, and spacing as a function of time. Much more work needs to be done in this respect so as to be able to test and compare coastal cities with inland cities as well as to compare the effects of the various landscape factors on city development and that of the associated street-network. New and more extensive datasets, from a variety of cities and landscapes, should provide a rigorous test of the methods used here and offer the possibility of putting the present results in a wider context of the general interaction between cities and landscapes.

\section{Acknowledgments}

We thank the two anonymous Entropy reviewers for very thorough reviews and helpful comments on an earlier version of this paper.

\section{Conflicts of Interest}

The authors declare no conflict of interest.

\section{References}

1. Kostof, S. The City Shaped: Urban Patterns and Meanings Through History; Thames and Hudson: London, UK, 1991.

2. Batty, M.; Longley, P. Fractal Cities: A Geometry of Form and Function; Academic Press: London, UK, 1994.

3. Batty, M. The size, scale, and shape of cities. Science 2008, 319, 769-771.

4. Levinson, D.; Huang, A. A positive theory of network connectivity. Environ. Plann. B 2012, 39, 308-325.

5. Scellato, S.; Cardillo, A.; Latora, V.; Porta, S. The backbone of a city. Eur. Phys. J. B 2006, 50, 221-225.

6. Hepcan, S.; Hepcan, C.C.; Kilicaslan, C.; Ozkan, M.B.; Kocan, N. Analyzing landscape change and urban sprawl in a Mediterranean coastal landscape: a case study from Izmir, Turkey. $J$. Coastal Res. 2013, 29, 301-310.

7. Shpuza, E. Urban shapes and urban grids: A comparative study of Adriatic and Ionian coastal cities. In Proceedings of the 6th Space Syntax Symposium, Istanbul, Turkish, 12-15 June 2007; 009-12. 
8. Shpuza, E. Evolution of street networks in Adriatic and Ionian coastal cities 1769-2007. In Proceedings of the 7th International Space Syntax Symposium, Stockholm, Sweden, 8-11 June 2009.

9. Mohajeri, M.; French, J.R.; Batty, M. Evolution and entropy in the organization of urban street patterns. Ann. GIS 2013, 19, 1-16.

10. Leopold, L.A.; Langbein, W.B. The Concept of Entropy in Landscape Evolution. US Geological Survey Professional Paper 500-A; US Government Printing Office: Washington DC, WA, USA, 1962; pp. 14-19.

11. Wilson, A.G. Entropy in urban and regional modelling: Retrospect and prospect. Geogr. Anal. 2010, 42, 364-394.

12. Wilson, A.G. Entropy in Urban and Regional Modelling; Pion: London, UK, 1970.

13. Levinson, D. Network structure and city size. PLoS One 2012, 7, e29721.

14. Xie, F.; Levinson, D. Topological evolution of surface transportation networks Comput. Environ. Urban 2009, 33, 211-223.

15. Jat, M.K.; Garg, P.K.; Khare, D. Monitoring and modelling of urban sprawl using remote sensing and GIS techniques. Int. J. Appl. Earth Obs. 2007, 10, 26-43.

16. Ghanghermeh, A.; Roshan, G.; Orosa, J.A.; Calvo-Rolle, J.L.; Costa, A.M. New Climatic Indicators for Improving Urban Sprawl: A Case Study of Tehran City. Entropy 2013, 15, 999-1013.

17. Ramachandra, T.V.; Bharath, H.A.; Durgappa, D.S. Insights to urban dynamics through landscape spatial pattern analysis. Int. J. Appl. Earth Obs. 2012, 18, 329-343.

18. Batty, M. Spatial entropy. Geogr. Anal. 1974, 6, 1-31.

19. Martins, R.D.A. Double exposure on the northern coast of the São Paulo State, Brazil. In Proceedings of the Berlin Conferences on Human Dimensions of Global Environmental Change, Berlin, Gemary, 8-9 October 2010.

20. Ferreira, L.C.; Barbi, F.; Martins, R.D.A.; Teixeira, L.R.; Urbinatti, A.M. Governing climate change in Brazilian coastal cities: Risks and strategies. In Proceedings of Colorado Conference on Earth System Governance: Crossing Boundaries and Building Bridges, Fort Collins, CO, USA, 17-20 May 2011.

21. Nicolodi, J.L.; Pettermann, R.M. Vulnerability of the Brazilian coastal zone in its environmental, social, and technological aspects. J. Coastal Res. 2011, 64 (Special Issue), 1372-1379.

22. Moura Jr. N.J.; Ribeiro, M.B. Zipf law for Brazilian cities. Physica A 2005, 367, 441-448.

23. Ferreira, J.C.; Silva, L.; Polette, M. The coastal artificialization process: Impacts and challenges for the sustainable management of the coastal cities of Santa Catarina. J. Coastal Res. 2009, 59, 1209-1213.

24. Rodrigues da Silva, A.N., da Silva Costa, M.; Macedo, M.H. Multiple views of sustainable urban mobility: The case of Brazil. Transp. Policy 2008, 15, 350-360.

25. Rodrigues da Silva, A.N.; Costa, G.C.F.; Brondino, N.C.M. Urban sprawl in Brazil and transportation energy use. Energy Sustainable Dev. 2007, 11, 171-185.

26. Rodrigues da Silva, A.N. Transport geography in Brazil. J. Trans. Geogr. 2012, 22, 324-326.

27. IBGE. Available online: http://www.ibge.gov.br/home/estatistica/populacao/censo2010/ (accessed on 4 March 2013).

28. Ordnance Survey. Available online: http://www.ordnancesurvey.co.uk/oswebsite/.co.uk/ (accessed on 8 October 2012). 
29. Haklay, M. How good is volunteered geographical information? A comparative study of OpenStreetMap and Ordnance Survey datasets. Environ. Plann. B 2009, 37, 682-703.

30. EDINA. Available online: http://www.edina.ac.uk/ (accessed on 2 May 2012).

31. Jiang, B.; Claramunt, C. Topological analysis of urban street networks. Environ. Plann. B 2004, 31, 151-162.

32. Newman, M. E. J. Power laws, Pareto distributions and Zipf's law. Contemp. Phys. 2005, 46, 323-351.

33. Jiang, B. Topological pattern of urban street networks: universality and peculiarity. Physica $A$ 2007, 384, 647-655.

34. Masucci, A.P.; Smith, D.; Crooks, A.; Batty, M. Random planar graphs and the London street network, Eur. Phys. J. B 2009, 71, 259

35. Chan, S.H.Y.; Donner, R.V.; Lammer, S. Urban road networks - spatial networks with universal geometric features? Eur. Phys. J. B 2011, 84, 563-577.

36. Ebdon, D. Statistics in Geography, 2nd ed.; Blackwell: Oxford, UK, 1985.

37. Shaw, G.; Wheeler, D. Statistical Techniques in Geographical Analysis; Wiley: New York, NY, USA, 1985.

38. Swan, A.R.H.; Sandilands, M. Introduction to Geological Data Analysis; Blackwell: Oxford, UK, 1995.

39. Smith, M.J.; Goodchild, M.F.; Longley, P. Geospatial Analysis: A Comprehensive Guide, 3rd ed.; Troubador Publishing Ltd.: Leicester, UK, 2009.

40. Nemec, W. The shape of the rose. Geology 1988, 59, 149-152.

41. GeOrient. Available online: http://www.holcombecoughlinoliver.com/ (accessed on 8 June 2012).

42. Schroeder, M. Fractals, Chaos, Power Laws; W.H. Freeman: New York, NY, USA, 1991.

43. Peitgen, H.O.; Jurgens, H.; Saupe, D. Chaos and Fractals, 2nd ed.; Springer Verlag: New York, NY, USA, 2004.

44. Pisarenko, V.; Rodkin, M. Heavy-Tailed Distributions in Disaster Analysis; Springer: Heidelberg, Germany, 2010.

45. Barabasi, A.L.; Albert, R. Emergence of scaling in random networks. Science 1999, 286, 509-512.

46. Clauset, A.; Chalizi, R.C.; Newman, M.E.J. Power-law distributions in empirical data. Soc. Ind. Appl. Math. 2009, 51, 661-703.

47. Hughes, I.G.; Hase, T.P.A. Measurements and Their Uncertainties; Oxford University Press: Oxford, UK, 2010.

48. Berendsen, H.J.C.; Data and Error Analysis; Cambridge University Press: Cambridge, UK, 2011.

49. Han, D.D.; Qian, J.H.; Ma, Y.G. Emergence of double scaling law in complex systems. Europhys. Lett. 2011, 94, 28006.

50. Kondepudi, D.; Prigogine, I. Modern Thermodynamics; Wiley: New York, NY, USA, 1998.

51. Stamps, A.E. Entropy and visual diversity in the environment. J. Archit. Plan. Res. 2004, 21, 239-256.

52. Nelson, P. Biological Physics: Energy, Information, Life; W.H. Freeman: New York, NY, USA, 2006.

53. Volkenstein, M.V. Entropy and Information; Birkhauser: Berlin, Germany, 2009.

54. Desurvire, E. Classical and Quantum Information Theory; Cambridge University Press: Cambridge, UK, 2009. 
55. Figueiredo, L. Continuity Lines: An investigation of urban form through street networks. Ph.D. Thesis, University College London, London, UK, 2009.

56. Goodman, S. A dirty dozen: Twelve $p$-value misconceptions. Semin. Hematol. 2008, 45, 135-140.

57. Wickers, A. What is P-Value Anyway? Addison-Wesley: Boston, MA, USA, 2010.

58. Brillouin, L. Science Uncertainty and Information; Academic Press: New York, NY, USA, 1964.

59. Blundell, S.J.; Blundell, K.M. Concepts in Thermal Physics; Oxford University Press: Oxford, UK, 2006.

60. Sethna, J.P. Statistical Mechanics: Entropy, Order, Parameters, and Complexity; Oxford University Press: Oxford, UK, 2006.

61. Mohajeri, N., Gudmundsson, A. Entropies and scaling exponents of street and fracture networks. Entropy 2012 14, 800-833.

(C) 2013 by the authors; licensee MDPI, Basel, Switzerland. This article is an open access article distributed under the terms and conditions of the Creative Commons Attribution license (http://creativecommons.org/licenses/by/3.0/). 